\title{
Pengaruh Customer Relationship Management (Crm) Terhadap Loyalitas Pengguna Irian Card (I-Card) Pada Irian Dept Store \& Supermarket Medan Marelan
}

\author{
Dinanti Nanda Pertiwi Siregar, Winda Cahyani, Ari Usman Chaniago \\ Sistem Informasi, Universitas Islam Negeri Sumatera Utara
}

\begin{tabular}{l}
\hline \hline Article Info \\
\hline Article history: \\
Received Jun $12^{\text {th }}, 2020$ \\
Revised Aug $20^{\text {th }}, 2020$ \\
Accepted Aug $26^{\text {th }}, 2020$ \\
\\
\hline Keyword: \\
Customer Relationship \\
Management \\
Loyalitas \\
Komitmen \& Kepercayaan \\
Orientasi Pelanggan, \\
Pengalaman, Komunikasi
\end{tabular}

\begin{abstract}
Penelitian ini membahas tentang pengaruh Customer Relationship Management yang terdiri dari 5 variabel yaitu: komitmen, kepercayaan, orientasi pelanggan/empati, pengalaman/kepuasan, dan komunikasi terhadap loyalitas pelanggan. Untuk mengetahui apakah ke-5 variabel Customer Relationship Management tersebut berpengaruh nyata terhadap loyalitas pelanggan, baik secara parsial maupun secara simultan, serta untuk mengetahui variabel manakah yang berpengaruh paling dominan terhadap loyalitas pelanggan. Penelitian ini dilakukan di Irian Dept Store \& Supermarket Medan Marelan, dengan populasi penelitian adalah konsumen yang belanja di Irian Dept Store \& Supermarket Medan Marelan dengan jumlah sampel yang diambil sebanyak 30 orang responden. Pengumpulan data dilakukan melalui kuesioner. Selanjutnya, data yang diperoleh dianalisis dengan menggunakan uji validitas, uji reliabilitas, analisis regresi linear berganda, uji t, dan uji F. Hasil penghitungan koefisien determinasi $\left(\mathrm{R}^{2}\right)$ adalah sebesar 0,866 , yang artinya; ke-5 variabel customer relationship marketing mempengaruhi variabel loyalitas sebesar $886,6 \%$.
\end{abstract}

\section{First Author}

Nama : Dinanti Nanda Pertiwi Siregar

Program Studi : Sistem Informasi

Universitas Islam Negeri Sumatera Utara

Email: Dinantisiregar6@gmail.com.

\section{PENDAHULUAN}

\subsection{Latar Belakang Masalah}

Tingkat persaingan bisnis yang semakin ketat menyebabkan banyak perusahaan yang kemudian tidak lagi memfokuskan aktivitas pemasaran mereka semata-mata pada pencarian pembeli baru, namun sudah lebih kepada usaha untuk mempertahankan dan meningkatkan kesetiaan pelanggan lama.

Menurut Shoemaker dan Lewis dalam Wijaya \& Thio (2008: 2), biaya untuk memperoleh pembeli baru dapat lima kali lebih mahal dibandingkan dengan biaya untuk memelihara pelanggan lama. Pelanggan yang loyal akan dengan senang hati mengungkapkan hal-hal yang positif dan memberikan rekomendasi mengenai perusahaan yang terkait kepada orang lain.

Turban, dkk (2002: 136) berpendapat bahwa Customer Relationship Management (CRM) adalah suatu pendekatan yang memandang bahwa pelanggan adalah inti dari bisnisnya dan keberhasilan suatu perusahaan tergantung dari bagaimana mereka mengelola hubungannya secara efektif.

Customer Relationship Management merupakan salah satu strategi dalam bidang pemasaran yang saat ini semakin banyak di implementasikan oleh perusahaan-perusahaan di Indonesia. Implementasi Customer Relationship Management banyak diterapkan pada perusahaan maskapai penerbangan, hotel, sampai perusahaan yang bergerak dalam bisnis supermarket dengan program kepemilikan membership card. Irian Dept Store \& Supermarket merupakan salah satu perusahaan retail yang sedang berkembang di Sumatera Utara dengan tagline "Belanja Murah Setiap Hari". Adapun irian supermarket ini menyajikan produk-produk terbaik yang ada dipasaran dengan harga yang sangat sesuai dengan segala kalangan masyarakat. Selain itu, 
Irian Dept Store \& Supermarket akan mendekatkan diri kepada konsumen dimana akan selalu disuguhkan dengan adanya promosi pada produk tersebut, adanya undian berhadiah roda rejeki, dan adanya penukaran barang-barang dengan point belanja yang telah ada di dalam kartu I-Card Irian Dept Store \& Supermarket tersebut.

Banyaknya perusahaan sejenisnya yang ada saat ini, seperti Suzuya, Maju Bersama, Alfamart, Indomaret dan lain-lain membuat perusahaan mereka berada di tengah persaingan ketat sehingga mereka memberi satu keistimewaan dengan bentuk pelayanan yang baik ke konsumen, selain kelengkapan produk, sirkulasi udara yang baik, jumlah barang yang ditata dengan baik, dan harga yang kompetitif, sesuai tagline "Irian, belanja murah setiap hari".

\subsection{Rumusan Masalah}

Dalam Penelitian Ini, Permasalahannya adalah :

1. Apakah Customer Relationship Management (CRM) yang terdiri dari lima variabel (komitmen, kepercayaan, orientasi pelanggan/empati, pengalaman/kepuasan, dan komunikasi) secara simultan maupun parsial mempunyai pengaruh yang signifikan terhadap loyalitas pengguna I-Card pada Irian Dept Store \& Supermarket Medan Marelan?

2. Manakah di antara ke-5 variabel Customer Relationship Management (CRM) (komitmen, kepercayaan, orientasi pelanggan/empati, pengalaman/kepuasan, dan komunikasi) yang berpengaruh paling dominan terhadap loyalitas pengguna I-Card pada Irian Dept Store \& Supermarket Medan Marelan?

\subsection{Tujuan Penelitian}

Untuk mengetahui apakah ke-5 variabel Customer Relationship Management tersebut berpengaruh nyata terhadap loyalitas pelanggan, baik secara parsial maupun secara simultan, serta untuk mengetahui variabel manakah yang berpengaruh paling dominan terhadap loyalitas pelanggan.

\section{KAJIAN PUSTAKA}

\subsection{Customer Relationship Management (CRM)}

Menurut Alma (2011), Customer Relationship Management (CRM) merupakan proses untuk mendapatkan, mempertahankan dan meningkatkan hubungan yang menguntungkan dengan pelanggan dalam rangka menciptakan nilai dan kepuasan pelanggan serta memaksimalisasi keuntungan perusahaan terkait keunggulan bersaing dan memperhatikan mutu produk agar pelanggan dapat mencapai kepuasan prima.

Faktor-faktor yang mempengaruhi CRM menurut Robinette dalam Febriningtyas (2013:20), ada empat faktor, yakni keuntungan bersama, komitmen, komunikasi, dan kualitas pelayanan.

Dimensi Customer Relationship Management (CRM) terdiri dari empat aktivitas, yaitu sebagai berikut.

a. Identify, yaitu mengidentifikasi pelanggan, misalnya dengan mengelola database dan membuat kartu member.

b. Acquire, yaitu mengakuisisi pelanggan dengan memberikan semua informasi kepada pelanggan, melayani dengan ramah dan sopan, menginformasikan promo melalui pesan singkat.

c. Retain, yaitu mempertahankan pelanggan dengan melakukan pemberian reward dan diskon.

d. Develop, yaitu upaya untuk mengembangkan atau mendapatkan pelanggan baru.

Manfaat Customer Relationship Management Menurut Tunggal (2000:10) dalam Achmad (2010), manfaat dari customer relationship management antara lain sebagai berikut.

a. Mendorong loyalitas pelanggan Customer relationship management memungkinkan perusahaan untuk mendayagunakan informasi dari semua titik kontak dengan pelanggan, mulai dari web, call center, hingga staf pemasaran dan pelayanan di lapangan. Konsistensi dan aksesibilitas informasi mengenai kondisi pelanggan di lapangan ini memungkinkan perusahaan untuk senantiasa memberikan pelayanan yang lebih baik kepada pelanggan.

b. Mengurangi biaya Pemanfaatan teknologi dalam customer relationship management dapat mengurangi biaya tertentu bagi perusahaan melalui sebuah skema program pemasaran terspesifikasi dan terfokus kepada pelanggan yang tepat di waktu yang tepat.

c. Meningkatkan efisiensi operasional Otomatisasi proses pelayanan dapat mengurangi risiko turunnya kualitas pelayanan, sekaligus mengurangi beban cash flow. Penggunaan teknologi web dan call center akan mengurangi hambatan birokrasi dan biaya serta proses administrasi yang ditimbulkannya.

d. Meningkatkan time to market Customer relationship management memungkinkan perusahaan untuk membawa produknya ke pasar secara lebih cepat dengan memanfaatkan data dan informasi yang lebih baik mengenai pelanggan dan trend pembeliannya, serta membuat perencanaan yang lebih baik melalui integrasi dengan aplikasi Enterprise Resource Planning (ERP). 
e. Meningkatkan pendapatan Customer relationship management memungkinkan perusahaan untuk melakukan penjualan dan menyediakan pelayanan melalui website, sehingga menciptakan peluang yang lebih besar bagi perusahaan untuk merambah pasar yang lebih luas dan global.

\subsection{Retail}

Kata retail sendiri berasal dari bahasa Perancis "ritellier", yang berarti memotong atau memecah sesuatu menjadi bagian yang lebih kecil. Sehingga, bisnis retail dapat dipahami sebagai semua kegiatan yang terkait dalam aktivitas penjualan dan menambah nilai barang (merchandise) atau jasa secara langsung kepada konsumen akhir untuk penggunaan pribadi dan bukan penggunaan bisnis. (Utami, 2008: 22)

Sementara, Berman \& Evans, dalam bukunya menyebutkan bahwa:

"Retailing encompasses the business activities involved in selling goods and services to consumers for their personal, family, or household use. It includes every sale to final consumer- ranging from cars to apparel to meals at restaurants to theater tickets. Retailing is the last stage in the distribution.

\subsection{Loyalitas Pelanggan}

Menurut Peter dan Olson (2005) dalam Achmad (2010), loyalitas pelanggan adalah dorongan untuk membeli suatu produk secara berulang-ulang dan membangun kesetiaan terhadapnya melalui proses pembelian yang berulang-ulang tersebut. Kotler dan Keller (2009) menyatakan bahwa loyalitas tidak hanya diukur dari banyaknya pembelian oleh konsumen, tetapi juga diukur dari banyaknya pembelian berulang oleh konsumen.

Tingkatan Loyalitas Pelanggan

Loyalitas memiliki enam tingkatan, yaitu sebagai berikut.

a. Suspect, yaitu semua pembeli produk yang menyadari adanya produk, tetapi terkadang tidak berkecenderungan untuk membeli.

b. Prospect, yaitu pelanggan potensial yang tertarik pada perusahaan, tetapi belum mengambil tindakan untuk berbisnis dengan perusahaan.

c. Customer, yaitu pembeli produk yang tidak loyal terhadap perusahaan, meski telah membeli beberapa kali.

d. Client, yaitu konsumen yang melakukan pembelian ulang dan menunjukkan loyalitas terhadap perusahaan, tetapi cenderung lebih pasif daripada aktif terhadap perusahaan.

e. Advocates, yaitu client yang memberikan dorongan positif kepada perusahaan dengan merekomendasikannya kepada orang lain.

f. Partners, yaitu pelanggan yang memiliki hubungan yang sangat erat dan saling menguntungkan.

\section{METODE PENELITIAN}

\subsection{Variabel Penelitian}

Customer Relationship Marketing (CRM), yang terdiri dari:

a. Commitment (komitment), (X1).

b. Trust (kepercayaan), (X2).

c. Customer orientation/empathy (orientasi pelanggan/empati), (X3).

d. Experience/satisfaction (pengalaman/kepuasan), (X4).

e. Communication (komunikasi), (X5).

\subsection{Tempat dan Lokasi Penelitian}

Penelitian ini dilakukan di Irian Dept Store \& Supermarket, yang beralamat di Jl. Marelan Raya Ps. II, Rengas Pulau, Kec. Medan Marelan, Kota Medan, Sumatera Utara 20255. Adapun objek penelitian ini adalah pengguna Irian Card (I-Card) yang terdaftar sebagai anggota I-Card yang aktif. Penelitian ini bersifat kausal, dimana penelitian memiliki tujuan yang jelas, yaitu menghubungkan sebab-akibat antara customer relationship marketing dan loyalitas pengguna I-Card di Irian Dept Store \& Supermarket Medan Marelan. Dalam penelitian ini, customer relationship management sebagai sebab, dan loyalitas pelanggan sebagai akibat (Sugiyono, 2007: 12).

\subsection{Populasi dan Sampel}

Adapun yang akan menjadi populasi dalam penelitian ini adalah konsumen yang berbelanja di Irian Dept Store \& Supermarket Medan Marelan. Sampel adalah bagian dari jumlah dan karakteristik yang dimiliki oleh populasi tersebut. Pengambilan sampel dalam penelitian ini dilakukan dengan menggunakan teknik Accidental Sampling yaitu objek yang kebetulan bertemu pada saat pengumpulan data dan sesuai untuk diteliti, hal ini dikarenakan semua mempunyai kemungkinan untuk dijadikan sebagai sampel penelitian. Dalam penelitian ini jumlah sampel yang ditentukan oleh peneliti adalah sebesar 30 responden 
Irian Dept Store \& Supermarket Medan Marelan, dengan alasan untuk penyesuaian dengan tingkat kemampuan, tenaga, dan waktu yang terbatas. Selain itu, dikatakan bahwa ukuran sampel 30 responden sudah dikatakan layak dalam suatu penelitian (Sugiyono, 2007).

\subsection{Metode Analisis Data}

Teknik skala pengukuran dengan menggunakan skala Likert. Pernyataan diberikan berjenjang dengan 5 (lima) kategori respons yaitu (1=sangat tidak setuju, 2=tidak setuju, 3=kurang setuju, 4=setuju, dan $5=$ sangat setuju). Sedangkan sumber data yang digunakan adalah data primer. Data diperoleh melalui kuesioner yang disebarkan kepada 30 responden di Irian Dept Store \& Supermarket Medan Marelan.

\section{HASIL DAN PEMBAHASAN}

4.1 Analisa Data Responden

Tabel 1 : Data Responden Menurut Usia

\begin{tabular}{|c|c|c|}
\hline Kelompok Usia (Tahun) & Jumlah (Orang) & Persentase (\%) \\
\hline$<20$ Tahun & 2 & 6,67 \\
\hline $20-25$ & 6 & 20 \\
\hline $26-30$ & 10 & 33,33 \\
\hline $31-40$ & 8 & 26,67 \\
\hline$>40$ & 4 & 13,33 \\
\hline Jumlah & $\mathbf{3 0}$ & $\mathbf{1 0 0}$ \\
\hline
\end{tabular}

Sumber: Data Primer Diolah, 2019.

Tabel 1. di atas menunjukkan bahwa dari 30 sampel, distribusi responden terpusat pada kelompok usia 26-30 tahun.

Tabel 2 : Data Responden Menurut Usia

\begin{tabular}{|c|c|c|}
\hline Jenis Kelamin & Jumlah (Orang) & Persentase (\%) \\
\hline Wanita & 22 & 73,33 \\
\hline Laki-Laki & 8 & 26,67 \\
\hline Jumlah & $\mathbf{3 0}$ & $\mathbf{1 0 0}$ \\
\hline
\end{tabular}

Sumber: Data Primer Diolah, 2019.

Tabel 3 : Data Responden Menurut Pendapatan Perbulan

\begin{tabular}{|c|c|c|}
\hline Pendapatan Perbulan(Rp) & Jumlah (Orang) & Persentase (\%) \\
\hline$<500.000$ & 2 & 6,67 \\
\hline $500.000-2.000 .000$ & 6 & 20 \\
\hline $2.000 .000-4.000 .000$ & 10 & 33,33 \\
\hline$>4.000 .000$ & 8 & 26,67 \\
\hline Jumlah & $\mathbf{3 0}$ & $\mathbf{1 0 0}$ \\
\hline
\end{tabular}

Sumber: Data Primer Diolah, 2019. 
Tabel 4 : Data Responden Menurut Pekerjaan

\begin{tabular}{|c|c|c|}
\hline Jenis Pekerjaan & Jumlah (Orang) & Persentase (\%) \\
\hline Pelajar/Mahasiswa & 1 & 3,33 \\
\hline PNS & 6 & 20 \\
\hline Pegawai Swasta & 10 & 33,33 \\
\hline Wiraswasta & 8 & 26,67 \\
\hline Ibu Rumah Tangga & 5 & 16,67 \\
\hline Jumlah & $\mathbf{3 0}$ & $\mathbf{1 0 0}$ \\
\hline
\end{tabular}

Sumber: Data Primer Diolah, 2019.

Tabel 5 : Data Responden Menurut Frekuensi Belanja

\begin{tabular}{|c|c|c|}
\hline Frekuensi Belanja & Jumlah (Orang) & Persentase (\%) \\
\hline 1 Kali & 2 & 6,67 \\
\hline 2 Kali & 7 & 23,33 \\
\hline 3 Kali & 9 & 30 \\
\hline 4 Kali & 10 & 33,33 \\
\hline$>4$ Kali & 2 & 6,67 \\
\hline Jumlah & $\mathbf{3 0}$ & $\mathbf{1 0 0}$ \\
\hline
\end{tabular}

Sumber: Data Primer Diolah, 2019.

\subsection{Analisa Statistika}

Uji Validitas dan Reliabilitas

Uji validitas yang dibahas ini adalah validnya sebuah item pertanyaan dalam kuisioner dengan jumlah 30 responden, maka sesuai dengan rumus $d f=n-2$ maka di dapat hasil $\mathrm{df}=302$ yaitu 28 . Berdasarkan kriteria dari ketentuan df atau degree of freedom yang sudah didapat dengan sig $5 \%(0,05)$, maka jika dilihat dari tabel $\mathrm{r}$ untuk df, di dapat hasil nilai $\mathrm{r}$ tabel sebesar 0,3610. Jika $\mathrm{r}$ hitung (korelasi item terhadap total korelasi) lebih besar dari $r$ tabel dan nilai $r$ positif, maka butir atau pertanyaan tersebut dinyatakan valid.

Uji Reliabilitas dapat dilakukan secara bersama-sama terhadap seluruh item pertanyaan dengan dasar pengambilan keputusan dalam uji reliabilitas adalah sebagai berikut :

a. Jika nilai Cronbach's Alpha > 0,60 maka kuisioner atau angket dinyatakan reliabel atau konsisten.

b. Jika nilai Cronbach's Alpha < 0,60 maka kuisioner atau angket dinyatakan tidak reliabel atau tidak konsisten.

Tabel 6 : Hasil Uji Reliabilitas

Item-Total Statistics

\begin{tabular}{|l|r|r|r|r|}
\hline & $\begin{array}{c}\text { Scale Mean if } \\
\text { Item Deleted }\end{array}$ & $\begin{array}{c}\text { Scale } \\
\text { Variance if } \\
\text { Item Deleted }\end{array}$ & $\begin{array}{c}\text { Corrected } \\
\text { Item-Total } \\
\text { Correlation }\end{array}$ & $\begin{array}{c}\text { Cronbach's } \\
\text { Alpha if Item } \\
\text { Deleted }\end{array}$ \\
\hline Komitmen & 17,27 & 2,271 & .201 & .475 \\
Kepercayaan & 16,90 & 1,748 & .563 & .196 \\
Orientasi_Pelanggan & 17,10 & 2,507 & .057 & .577 \\
Kepuasaan & 16,63 & 2,033 & .566 & .256 \\
Komunikasi & 16,77 & 2,668 & .067 & .542 \\
\hline
\end{tabular}


Data reliabilitas pada tabel 6 sudah reliabel yaitu hasil dari masing-masing Cronbach's Alpha menunjukkan nilai $>0,60$.

Hasil Analisis Regresi Linier Berganda

Hasil analisis regresi linier berganda di lakukan dengan menggunakan bantuan SPSS Versi 22.0, sehingga menghasilkan data seperti tabel di bawah ini :

Tabel 7 : Nilai Koefisien Regresi, $t$ hitung, $t$ tabel, $F$ hitung, $F$ tabel, Koefisien Determinasi $\left(\mathbf{R}^{2}\right)$, dan koefisien Korelasi Berganda $(\mathbf{R})$

\begin{tabular}{|c|c|c|c|c|c|}
\hline Variabel & $\begin{array}{c}\text { Koefisien } \\
\text { Regresi }\end{array}$ & Nilai t hitung & Nilai t tabel & $\begin{array}{l}\text { Nilai F } \\
\text { hitung }\end{array}$ & Nilai F Tabel \\
\hline Konstanta (a) & 0,016 & 0,009 & 1,697 & 30,898 & 2,55 \\
\hline Komitmen (X1) & 1,476 & 6,030 & 1,697 & 30,898 & 2,55 \\
\hline Kepercayaan (X2) & 1,417 & 4,562 & 1,697 & 30,898 & 2,55 \\
\hline Orientasi_Pelanggan (X3) & 0,707 & 3,132 & 1,697 & 30,898 & 2,55 \\
\hline Kepuasan (X4) & $-0,189$ & $-0,464$ & 1,697 & 30,898 & 2,55 \\
\hline Komunikasi (X5) & 1,598 & 5,684 & 1,697 & 30,898 & 2,55 \\
\hline \multicolumn{6}{|c|}{ Koefisien Determinasi $(\mathrm{R} 2)=0,866$} \\
\hline \multicolumn{6}{|c|}{ Koefisien Korelasi Berganda $(\mathrm{R})=0,930$} \\
\hline $\mathrm{N}=30$ & & & & & \\
\hline
\end{tabular}

Dengan hasil seperti di atas, peneliti dapat mengetahui nilai konstanta dan nilai koefisien regresi dari masing-masing variabel, dengan persamaan regresi linear berganda sebagai berikut: $\mathrm{Y}=0,016+1,476 \mathrm{X} 1+1,417 \mathrm{X} 2+0,707 \mathrm{X} 3-0,189 \mathrm{X} 4+1,598 \mathrm{X} 5+\mathrm{e}$

Dari hasil di atas, tampak bahwa variabel kepuasan memiliki hubungan yang berbanding terbalik dengan variabel loyalitas. Hal ini disebabkan karena tingkat loyalitas pengguna I-Card di Irian Dept Store \& Supermarket cukup tinggi, namun tingkat kepuasan cukup rendah. Namun secara total, variabel CRM memberi kontribusi pengaruh sebanyak 86,6\%, yang artinya, variabel CRM mampu mempengaruhi loyalitas sebanyak $86,6 \%$. Sementara itu, hasil pengujian statistik untuk uji t dan uji F disajikan dalam tabel berikut:

Tabel 8 : Nilai Koefisien Regresi dan Nilai Hitung Uji Coefficients ${ }^{a}$

Coefficients $^{a}$

\begin{tabular}{|c|c|c|c|c|c|c|}
\hline \multirow[b]{2}{*}{ Mod } & & \multicolumn{2}{|c|}{ Unstandardized Coefficients } & \multirow{2}{*}{$\begin{array}{c}\begin{array}{c}\text { Standardized } \\
\text { Coefficients }\end{array} \\
\text { Beta }\end{array}$} & \multirow[b]{2}{*}{$\mathrm{t}$} & \multirow[b]{2}{*}{ Sig. } \\
\hline & & B & Std. Error & & & \\
\hline \multirow[t]{6}{*}{1} & (Constant) &, 016 & 1,893 & &, 009 &, 993 \\
\hline & Komitmen & 1,476 &, 245 &, 503 & 6,030 &, 000 \\
\hline & Kepercayaan & 1,417 &, 311 & , 467 & 4,562 &, 000 \\
\hline & Orientasi_Pelanggan & .707 &, 226 &, 252 & 3,132 &, 005 \\
\hline & Kepuasaan &,- 189 &, 407 &,- 049 &,- 464 & 647 \\
\hline & Komunikasi & 1,598 & 281 & 463 & 5,684 &, 000 \\
\hline
\end{tabular}

Model Summary

\begin{tabular}{|l|r|r|r|r|}
\hline $\begin{array}{c}\text { Model } \\
\text { Summary } \\
\text { Model }\end{array}$ & R & R Square & $\begin{array}{c}\text { Adjusted R } \\
\text { Square }\end{array}$ & $\begin{array}{c}\text { Std. Error of } \\
\text { the Estimate }\end{array}$ \\
\hline 1 &, $930^{\mathrm{a}}$ &, 860 &, 838 &, 783 \\
\hline
\end{tabular}

Predictors: (Constant), Komunikasi, Orientasi_Pelanggan, Komitmen, Kepercayaan, Kepuasaan 
Dependent Variable : Loyalitas

Dari hasil yang tampak pada tabel di atas, ditemukan bahwa terdapat satu variabel yang tidak berpengaruh nyata terhadap variabel loyalitas (karena nilai t hitung lebih kecil dari nilai t tabel), yaitu variabel kepuasan. Dan variabel yang paling dominan adalah variabel komitmen dan komunikasi.

Sementara nilai uji F disajikan dalam tabel berikut:

ANOVA $^{\mathrm{a}}$

\begin{tabular}{|ll|r|r|r|r|r|}
\hline Model & & \multicolumn{1}{c|}{$\begin{array}{c}\text { Sum of } \\
\text { Squares }\end{array}$} & df & Mean Square & F & Sig. \\
\hline 1 & Regression & 94,747 & 5 & 18,949 & 30,898 &, $000^{\mathrm{b}}$ \\
& Residual & 14,719 & 24 &, 613 & & \\
& Total & 109,467 & 29 & & & \\
\hline
\end{tabular}

a. Dependent Variable: Loyalitas

b. Predictors: (Constant), Komunikasi, Orientasi_Pelanggan, Komitmen, Kepercayaan, Kepuasaan

Dengan nilai $\mathrm{F}$ hitung sebesar 30,898, lebih besar dari nilai $\mathrm{F}$ tabel (2.55), menunjukkan bahwa CRM yang terdiri dari 5 variabel bebas (komitmen, kepercayaan, orientasi/empati, pengalaman/ kepuasan, dan komunikasi) secara serentak berpengaruh nyata dan signifikan terhadap loyalitas pelanggan (pengguna ICard).

\section{KESIMPULAN}

Variabel customer relationship marketing yang terdiri dari komitmen, kepercayaan, orientasi pelanggan/empati, pengalaman/kepuasan, dan komunikasi secara simultan mempunyai pengaruh yang signifikan terhadap loyalitas pengguna I-Card. Dari ke-5 variabel customer relationship marketing, variabel yang berpengaruh secara dominan terhadap loyalitas pengguna I-Card adalah variabel komunikasi dengan koefisien regresi (b) sebesar 1,598 dan nilai thitung sebesar 5,684.

Secara keseluruhan, pengguna I-Card memiliki komitmen, kepercayaan, empati, kepuasan dan komunikasi yang baik dengan Irian Dept Store \& Supermarket Medan Marelan, demikian juga Irian Dept Store \& Supermarket Medan Marelan memiliki komitmen, kepercayaan, orientasi pelanggan, empati, kepercayaan dan menjalin komunikasi dengan pengguna I-Card. Customer relationship marketing yang terjalin antara pengguna I-Card dan Irian Dept Store \& Supermarket Medan Marelan sudah baik.

\section{DAFTAR PUSTAKA}

1. Achmad, T. (2010). Pengaruh Customer Relationship Marketing Terhadap Loyalitas Pengguna Matahari Club Card (MCC) Pada Matahari Department Store Mal Ska Pekanbaru. Jurnal Ekonomi, 4.

2. Alma, B. (2011). Manajemen Pemasaran dan Pemasaran Jasa. Bandung: Alfabeta.

3. Febrianingtyas. (2013). Pengaruh Customer Relationship Management terhadap Kepuasan dan Loyalitas Nasabah. Media, 20.

4. Kotler, P. \&. (2009). Marketing Management. 13th Ed. New Jersey: Pearson Prentice Hall.

5. Peter, J. d. (2005). Consumer Behaviour and Marketing Strategy. 7th Edition. New York: McGraw-Hill.

6. Sugiyono. (2007). Statistika untuk Penelitian. Bandung: Alfabeta.

7. Tunggal, A. (2000). Konsep Dasar Customer Relationship Management. Jakarta: Harvarindo.

8. Turban, E. K. (2002). Electronic commerce a managerial perspective. Pearson education inc. New Jersey: Upper Saddle River.

9. Whidya, U. C. (2008). Relationship Effort Dan Kualitas Layanan Sebagai Strategi Penguat Relationship Outcomes. Jurnal Manajemen Pemasaran, 22-34.

10. Wijaya, S. d. (2008). Implementasi Membership Card dan Pengaruhnya dalam Meningkatkan Loyalitas Pengunjung Restoran.serliw@ peter.petra.ac.id.www.puslit.petra.ac.id/journals/journals. 